\title{
Balthazar Claës e a demanda do solvente universal, o alkahest
}

\author{
A.M. Amorim da Costa \\ Departamento de Química, Universidade de Coimbra \\ acosta@ci.uc.pt
}

\begin{abstract}
The chemical quest of the universal solvent by Balthazar Claës - Based on the philosophical novel of Honoré Balzac (1799-1850) "La recherche de l'Absolu” written in 1834, in this work we refer to the possible existence and chemical nature of an universal solvent.

Em 1834, Honoré Balzac escreveu “A Procura do Absoluto”, um dos seus muitos escritos filosóficos, uma novela em que o personagem central é Balthazar Claës, Conde de Nourho, e senhor da Casa de Claës, em Douai, um homem apaixonado pela ciência em geral, e pela química, em particular, que a partir de certa altura se devotou por completo à procura do solvente universal, o alkahest, até à ruina completa da fortuna que possuía. Num misterioso e feliz achado, acabaria recompensado e reconciliado consigo: encontrou o seu solvente universal.
\end{abstract}

\section{Balthazar Claës}

Ao concluir a sua educação, em Paris, por volta de 1783, Balthazar Claës, então com vinte e dois anos, era aquilo que em França se considerava um "belo Homem” [1]. Porém, quando em 1812 o encontramos na sala de estar de sua casa, em Douai, com sua mulher, contando pouco mais de cinquenta anos, a sua figura era tudo menos isso: alto de estatura, aparecia totalmente curvado, com a cabeleira loira pouco cuidada, caída sobre os ombros, a pele colada aos ossos, a testa enrugada como a de um rei cheio de cuidados, com as mãos grandes, cabeludas e sujas, unhas compridas, com linhas pretas muito pronunciadas nas extremidades, os sapatos por engraxar e sem cordões, as calças de fazenda preta cheias de nódoas, o colete desapertado, a sobrecasaca esverdeada descosida, revelando uma total negligência, apanágio de um génio alheado do presente e totalmente absorto nos seus trabalhos secretos [2].

Nascido por volta de 1759, Balthazar Claës, para além de um "belo homem", foi nos seus tempos de juventude um homem rico e culto. Em Paris, foi aluno de Lavoisier com quem estudou e se interessou pela ciência química e se familiarizou com os escritos de Fourcroy, Chaptal, Nollet, Rouelle, Bertholet, Gay-Lussac, e também, entre outros, com os escritos de Spallanzani, Leuwenhoëk, Galvani e Volta [3]. Conde de Nourho, casou em 1795, com Mademoiselle de Temninck, dando início a mais de uma quinzena de anos de grande harmonia, felicidade e grande bem-estar material, em Douai, na casa patriarcal de Claës. A casa era uma casa rica em mobília de grande valor, com belas obras de arte de artistas de renome, nomeadamente Murillo e Velasquez, e muitos objetos preciosos de valor inestimável. Rapidamente, a toda a riqueza material da casa se juntou a riqueza sem preço de quatro filhos, duas raparigas e dois rapazes que espalhavam alegria a rodos por todos os cantos.

Repentinamente e sem nada o fazer esperar, em 1810 , toda esta situação de felicidade e bem-estar sofreu um duro golpe e amargo volte-face que se prolongaria por longos anos. Tudo começou no ano anterior, em 1809, no dia em que Balthazar de Claës alojou em sua casa o matemático polaco Adam Wierzchownia, decalque real do polaco nascido em Poznam, Joseph-Marie Hoëne Wronski, (1776-1853). Adam Wierzchownia, oficial de artilharia, fora feito prisioneiro, em 1792, em Varsóvia, quando da guerra pela independência. Dois anos depois, tendo conseguido a sua libertação, refugiou-se por vários anos na Suécia, donde passaria para França. Aqui alistou-se no exército francês. Nos anos que viveu na Suécia, dedicou-se intensa e apaixonadamente ao estudo das matemáticas e da química, e tornou-se num fervoroso místico, devotado a práticas esotéricas, com escritos vários sobre o absoluto.

Um dia, de passagem por Douai, Adam Wierzchownia procurara, em vão, uma estalagem para pernoitar. Não tendo encontrado nenhuma disponível, alguém lhe sugeriu que batesse à porta da casa dos Claës, casa grande e sempre hospitaleira. Assim o fez, e nela foi acolhido com grande prodigalidade [4].

Logo na primeira noite em que ficou em casa dos Claës, Adam Wierzchownia, antes de recolher aos seus aposentos para dormir, passou algumas horas na sala da biblioteca a sós com Balthazar, conversando com ele sobre química. Repetiu este convívio, por algumas vezes mais, nos dias seguintes. As conversas havidas eram inflamadas e apaixonantes para ambos e abrangiam praticamente todas as matérias da química inorgânica e da química orgânica.

Segundo A. Wierzchownia todos os produtos da natureza do reino orgânico se reduziriam a quatro corpos simples, resumidos a três gases, o nitrogénio, o hidrogénio e o oxigénio e a um outro corpo simples, não metálico e sólido, o carbono [5]. No mundo inorgânico haveria um muito maior número de corpos simples, nada menos do que cinquenta e três, cujas diferentes combinações originavam todos os compostos do reino inorgânico. Todos estes cinquenta e três corpos possuiriam um princípio comum, modificado outrora pela ação de um poder hoje extinto, mas que o génio humano poderia fazer reviver. $\mathrm{O}$ ponto de partida desta ação seria conseguir decompor o nitrogénio, tarefa esta perante a qual a química moderna não deveria nunca recuar, pois ela é uma ciência que se acostumou a não recuar perante nenhuma dificuldade. 
Afoito, A. Wierzchownia, sabendo-se na presença de um discípulo fervoroso de Lavoisier e um homem rico e que podia dispor livremente de todo o seu tempo, falou-lhe abertamente das suas conjeturas e das experiências pessoais que já tivera em curso para realizar essa tarefa, em trabalhos aturados que "foram interrompidos pela guerra e pela miséria” [6].

E, com toda a convicção, avançou com o substrato da posição filosófica que deduzira já da sua experiência: “deduzi a existência do Absoluto! Uma substância comum a todas as criações, modificada por uma força única; (...) “a Matéria Una deve ser um princípio comum aos três gases e ao carbono. O Meio deve ser o princípio comum à eletricidade negativa e à eletricidade positiva”; (...) procuro obcecadamente "esse princípio pelo qual sementes, absolutamente semelhantes, colocadas num mesmo meio, produzem, uma corolas brancas, a outra corolas amarelas!”; princípio aplicável ao próprio homem que tantas vezes tem legitimamente filhos totalmente diferentes dele e da mãe”; E perguntava-se: “A Adoração pitagórica do UNO, de onde saem todos os números e que representa a matéria una; a do número DOIS, a primeira agregação e o protótipo de todas as outras; a do número TRÊS, que em todos os tempos configurou Deus, isto é, a Matéria, a Força e o Produto, não resumirão elas tradicionalmente o conhecimento confuso do Absoluto?” E concluía com toda a convicção: Stahl, Becher, Paracelso, Agripa e todos os grandes pesquisadores de causas ocultas sempre tiveram como palavra de ordem o Trismegisto, que quer dizer grande ternário. Os ignorantes, habituados a condenar a alquimia, essa química transcendente, não sabem certamente que nós nos ocupamos a justificar as pesquisas apaixonantes desses grandes homens! Encontrando o Absoluto, lutaria então com o movimento; sem o encontrar, alimento-me de pólvora e mando homens inutilmente para a morte" [7].

Balthazar Claës não resistiu às palavras convictas e inflamadas de Wierzchownia havidas nessas conversas de serão, noite fora. Foram vãs todas as palavras de sua mulher tentando dissuadi-lo de seguir o que ouvira do oficial polaco que tão gentilmente recebera em sua casa e tentando fazer-lhe ver que elas eram palavras de Satã, o Tentador, que tudo estava fazendo para o levar a deixar de ser o bom pai, esposo e chefe de família que sempre fora. Esquecendo tudo e todos os que o rodeavam, fazendo tábua-rasa de tudo o que ouvia vindo de quem o rodeava, Balthazar mergulhou totalmente na ciência do Absoluto que o levava no seu dorso e de asas abertas, para muito longe do mundo material. Em tudo e à custa de tudo passou a procurar o Absoluto, o Elixir da Longa Vida, o Solvente Universal, o alkahest. Nessa procura, fez de sua casa um grande laboratório onde analisou todas as flores, frutos e licores que pôde e onde foi queimando quantas pedras preciosas e diamantes tinha à mão e os mais variados vegetais e minerais sempre na esperança de ver desprender-se da sua combustão a matéria etérea que fosse a palavra do Absoluto, que fosse o Elixir que procurava, que fosse o almejado Solvente Universal. Com o mesmo intuito tentou a decomposição de tudo por mais que lhe dissessem que “decompor não é criar”.

Esqueceu e desleixou o seu ser físico; a esposa acusava-o de tentar a Deus e de cometer o mesmo pecado de orgulho que levou à perdição do Anjo das Luzes e dele fez o perverso Demónio, e lamentava-se de ter ele devorado para arranjar o carvão necessário à manutenção dos fornos, mais de novecentos mil francos em apenas três anos. Para suprir suas necessidades, a esposa teve de vender muitas das propriedades e muitas das velhas pratas que eram orgulho da Casa. Nada o demovia da sua procura, por mais que a esposa lhe fosse dizendo que "a ciência lhe estava a devorar o coração" [8].

Os anos passaram até que um dia, com tudo a correr mal, Balthazar, acompanhado pelo seu fiel ajudante Lemulquinier, subiu ao sótão onde se encontrava o laboratório, disposto a lançar um olhar cheio de melancolia a toda a aparelhagem com que trabalhara e dizer adeus a todas as esperanças que tanto acalentara mas em vão; e fazendo-o desaparecer. A casa estava arruinada e cheia de dívidas, com os credores prontos a cobrá-las sem dó nem piedade. Para trás ficavam as suas muitas tentativas de cristalização do carbono. Persistente e acreditando sempre num feliz desfecho em que as suas experiências haveriam de resultar, os seus olhos demoraram-se sobre uma cápsula na qual mergulhavam dois fios de uma pilha de Volta na qual utilizava uma combinação de carbono e de enxofre em que o carbono desempenhava o papel de corpo eletropositivo, num processo de cristalização do carbono, caso houvesse decomposição, no polo negativo, e, com o abaixamento da temperatura, a cristalização do sulfureto de carbono, o solvente universal que tanto procurava, se daria.

Não tinha, todavia, a certeza se a experiência acabaria ou não por funcionar. Era preciso deixá-la como estava, em total repouso, e dar tempo ao tempo, condições essenciais para a almejada cristalização, cujos trabalhos ele e o seu empregado acabavam de abandonar, sem tempo para esperar mais, antes de partir para um último almoço com a família e se despedir dos filhos, partindo de seguida para a Bretanha, onde iria gerir uma Repartição de Finanças, ofício para que fora convidado e, face à miséria em que se encontrava, sentira ser obrigação sua aceitar. A filha mais velha, Margarida, e outros familiares amigos cuidariam de saldar as dívidas e salvar das ruínas a casa de Claës. Ele haveria de voltar um dia para assistir à feliz recuperação dos bens e riquezas perdidos. Partia pois, absolutamente convencido que o solvente universal que procurava, o alkahest, a matéria mãe de todas as matérias e de tudo que há nos reinos animal, vegetal e mineral, não estava longe: iria surgir da cristalização do sulfureto de carbono na experiência que deixava a correr no seu laboratório.

\section{O solvente universal}

Quais as virtudes esperadas desse cristal? Para Balthazar Claës, ele seria um diamante muito especial que conteria em si, simultaneamente, as virtudes e poderes da Pedra Filosofal dos alquimistas e do Elixir da Longa Vida da química espagírica.

Capaz de dissolver todas as substâncias, incluindo o ouro, o alkahest teria qualidades medicinais que se não conseguiria encontrar em mais nenhuma outra substância. Muito procurado e apregoado, ele seria "um licor capaz de decompor todo e qualquer corpo visível na sua matéria-prima, isolando a força de suas sementes iniciais”. Foi Paracelso (1493-1541), o pai da iatroquímica, quem primei- 
ro aludiu à existência desse composto ao referir-se no seu Tractatus de viribus membrorum spiritualium (Tratado espiritual das forças dos membros), obra póstuma publicada em 1572 [9], no capítulo sobre como curar as doenças do fígado, a um solvente que as preservaria, designando-o por alkahest, sem dizer onde foi buscar o vocábulo, que tanto poderá ter sido para significar tratar-se do alcali por excelência, alkali est (= é o alkali), como para conferir ao licor em causa uma aura misteriosa associando-o às práticas químicas dos árabes. Jean B. van Helmont (1580-1644), seu discípulo, e possivelmente um dos químicos mais influentes no desenvolvimento posterior da iatroquímica, adotou a terminologia e defendeu que o alkahest era "uma das maiores maravilhas da química"- o interesse de Jean B. van Helmont nesta "maravilha da química" era apenas medicinal: uma substância capaz de reter os prima entia de cada corpo e um modo seguro e não destrutivo de obter as virtudes médicas de qualquer corpo "simples". Seria assim, o remédio contra todas as doenças que só poderia ser conseguido como "um presente de Deus para alguém que merecesse essa graça” [10]. Afirmando as suas virtudes de remédio universal, capaz de curar todas as doenças, J.B. van Helmont tinha-o como um corpo metálico cuja descoberta e preparação atribuia a seu mestre Paracelso e a que só os verdadeiros “adeptos alquímicos” seriam capazes de ter acesso [11-13]. Parte importante da doutrina de van Helmont sobre o solvente universal é resultado da doutrina que defendeu sobre a natureza da água e as semina dos corpos naturais, os seus princípios constituintes, e também das suas teorias sobre a função e importância dos fermentos, os princípios químicos atuantes em todos os corpos. Concretamente, quanto à água, defendeu convictamente o seu caráter elementar e omnipresente. Em particular, tornaram-se muito populares e muito famosas as experiências que fez com um pequeno arbusto de salgueiro, rigorosamente pesado (5 libras $=2,27 \mathrm{~kg}$ ) antes de plantado num recipiente contendo 200 libras ( $=90,72 \mathrm{~kg}$ ) de terra, pesada também com todo o cuidado e rigor, e regado durante cinco anos só com água pura. No fim destes anos, o arbusto foi devidamente limpo de toda a terra que a ele aderira e novamente pesado, tendo concluído que o aumento do seu peso se devia apenas à água com que fora regado, da qual se teriam formado todos os demais elementos necessários ao seu crescimento. Do verificado concluiu que a água é um elemento primitivo, indestrutível e inalterável [14], sublinhando a doutrina de Tales que apoiando-se no papel de primordial importância que a água desempenha na natureza, defendeu ser ela a "substância universal de que todas as coisas são feitas, a matéria-prima única de que tudo deriva” [15] e alinhava com a crença de quantos continuavam a afirmar ser ela "a filha mais velha do Criador, o elemento sobre que primeiramente se moveu o Espírito de Deus, o Elemento a que Deus ordenou que desse abundantemente origem a todas as criaturas" [16]. Foi o primeiro passo para se vir a tentar identificar, mais tarde, o alkahest com a própria água.

De facto, deve-se muito à influência da doutrina química de J. B. van Helmont sobre os químicos que se lhe seguiram, a centralidade que o tema do solvente universal, o alkahest, um solvente que dissolvesse praticaments todas as substâncias conhecidas e não fosse “marcado” por ne- nhuma delas, teve nos escritos e nas investigações químicas de muitos deles. Para o comprovar, evocaremos aqui apenas o teor das investigações e trabalhos referidos por R. Boyle (1627-1691) no seu The Sceptical Chymist [17] e a marca que tiveram sobre os seus sequazes mais próximos. Sob a influência das doutrinas de J. B. van Helmont, Boyle dedicou uma grande parte das suas primeiras investigações em química à procura do solvente universal, o alkahest, considerando-o o grande instrumento para decompor os corpos, de longe muito melhor e mais eficaz que o fogo que era usado até então, como o instrumento principal na análise química. Boyle refere ser este solvente universal um sal ou mênstruo, incomparavelmente superior a qualquer outro agente químico, não alterável nas operações químicas ordinárias como o eram os espíritos salinos comuns.

Em particular, foram caixa de ressonância importante das investigações de Boyle nesta matéria, o médico e alquimista Eirenaeus Philalethes, pseudónimo do americano George Starkey (1628-1665), e também o médico e químico alemão Frederick Clodius (1625-1661) e, ainda vários dos mais notados filósofos naturais ligados ao chamado círculo de Hartlib [18].

Muito concretamente, em 1651, Starkey escrevia a Boyle, falando-lhe não só da possibilidade do alkahest, mas também da sua preparação a partir do ácido acético [19]. E não seria o único a referir-se, nesses anos, a um modo de o preparar. Por um documento escrito em Latim [20,21], em que se relata o que se passou numa série de quatro reuniões que tiveram lugar na Royal Society de Londres nos meses de outubro e novembro de 1661, em que os académicos discutiram a ação fisiológica ligada às descobertas feitas, em 1653, pelo médico, matemático e teólogo dinamarquês Thomas Bartholin (1616-1680), e também e ao mesmo tempo, pelo Professor de Medicina na Universidade de Uppsala, Olof Rudbeck (1630-1702) sobre a existência do sistema linfático. Na sequência da discussão havida, Henry Oldenburg (1619-1677), na qualidade de primeiro-secretário da Sociedade, escreveu ao cirurgião militar das forças de Oliver Cromwell, Jonathan Goddard (1617-1675), também ele membro proeminente e muito ativo da Sociedade, pedindo-lhe que analisasse as descobertas expostas e verificasse se o líquido que nelas se usava tinha alguma coisa a ver com o chamado alkahest e fizesse as observações necessárias que lhe permitissem concluir sobre os prós e os contras da possibilidade de tal líquido ser o próprio solvente universal que tantos procuravam. Os resultados das observações de Jonathan Goddard foram objeto de um parecer emitido pelo próprio J. Goddard que Oldenburg submeteu à apreciação da Sociedade em novas reuniões. Na sua apreciação, os académicos fizeram questão de deixar claro que a preparação fisiológica ligada às descobertas de Thomas Bartholin e Olof Rudbeck, não era o verdadeiro e procurado solvente universal, mas nela havia um licor que para muitos era um verdadeiro alkahest animal e para o qual o próprio J. Goddard referia uma receita que deveria ser considerada com toda a ponderação, pelo que o documento deveria ser cuidadosamente guardado para análise subsequente mais pormenorizada. Oldenburg era um dos académicos mais convictos da existência dessa receita.

Numa viagem ao Continente, Oldenburg encontrara-se com o médico Johann Christoph Kohlhans (1604-1677), 
seu amigo, e também amigo fraternal de Franciscus-Mercurius van Helmont (1614-1699), o filho de J. B. van Helmont e editor póstumo de suas obras, e possivelmente, também fiel depositário da fórmula do alkahest de Paracelso deixada por seu pai.

A crença na existência do alkahest e a investigação sobre a sua possível preparação continuava pois, bem viva, abraçada pela própria Royal Society a que pertenciam os mais reconhecidos filósofos naturais da época. E foi-se mantendo por muito tempo, resistindo às mais variadas investidas das emergentes teorias mecanicistas, em luta aberta a receituários herméticos, na passagem de uma crença alquimista, baseada numa cadeia de mistérios, para um universo racional, mecanicista. A alquimia não desapareceu por completo com o triunfo da visão mecânica e corpuscular.

A afirmar a sua existência e a utilizá-lo como tal, não falta quem defendesse ser ele a Água, por mais que seja imperioso reconhecer que ela não dissolve todas as substâncias conhecidas. A crença no poder curativo universal da água é uma crença muito universal e que vem de tempos imemoriais, plasmada na prática de muitos e diversos povos e consagrada na sigla latina dos romanos spa (salus per aquam = saúde pela água) [22]. Pese embora as suas propriedades únicas que lhe permitem dissolver muitas e muitas outras substâncias, não dissolve, como seria de esperar de um dissolvente universal, um grande número delas, nomeadamente, as substâncias não-polares, por sua natureza hidrofóbicas. O facto é que ela representa mais de $70 \%$ dos fluidos que fazem parte da composição de todos os seres vivos e daí o ser agente determinante da maioria dos problemas de saúde/doença objeto de atuação da iatroquímica. Ela é uma substância absolutamente necessária à existência da vida.

Nas malhas da ciência moderna, os defensores do alkahest continuaram e continuam a procurá-lo. Se para os alquimistas, a prata não é necessariamente a prata, nem o mercúrio ou o enxofre, são o mercúrio ou o enxofre que os químicos manuseiam nos seus laboratórios, também o dissolvente universal de Paracelso, o alkahest da iatroquímica, não tem de ser necessariamente um líquido que dissolva todas as demais substâncias. Poderá ser um metal, um sal, um líquido; não importa o quê. Para quem nele crê e continua a procurá-lo, o que interessa verdadeiramente são as suas qualidades medicinais que não conseguem encontrar em mais nenhuma outra substância.

Seja ele a água ou um outro licor qualquer, do alkahest identificável com o solvente universal espera-se que seja o medicamento universal para toda e qualquer doença com que o verdadeiro praticante de medicina se tenha de confrontar. Por isso ele é objeto de tão grande procura, em todos os tempos e lugares, hoje como ontem, o que nos permite concluir que ele é o grande mistério e romance da alquimia, como se the referiu o médico e escritor Charles John Samuel Thompson (1862-1943) [23]: ele é, e continuará a sê-lo, a força vital de tudo quanto vive, o tocar do eterno e a compreensão do misterioso, o Absoluto, a cuja procura Balthazar Claës pela pena de Honoré Balzac acabou por dedicar o melhor de sua vida de homem devotado à ciência, em particular à ciência química.

\section{Referências}

[1] H. Balzac, La recherche de l'Absolu, 1834, in A comédia Humana, Livraria Civilização Editora, Barcelos, 1981, vol. XV, A Procura do Absoluto, p. 20.
[2] Idem, p. 18.

[3] Idem, p. 40.

[4] Idem pp. 50ss.

[5] Idem p. 51.

[6] Idem p. 53.

[7] Idem, pp. 53-54.

[8] Idem, p. 56

[9] Ph. Theof. Paracelsi, Tractatus de viribus membrorum spiritualium, Ed. Bernard Jobin, Strassburg, 1572.

[10] J.B. van Helmont, Opuscula medica inaudita, Cologne, 1644, sig. A4v.

[11] L. Reti, Van Helmont, Boyle and the alkahest in some aspects of the Seventeenth Medicine in Science, Los Angeles, UCLA, W Andrews Clark Mem, Lib, 1969, Pt. I.

[12] P.A. Porto, Summus atque felicissimus salium: the medical relevance of the liquor alkahest, Bull. Hist. Med. 76, Spring 2002, 1-29.

[13] B. Joly, The alkahest, universal dissolvent or when theory turns an impossible practice into the imaginable, Rev. Hist. Sci. Paris 49 (1996) 305-344.

[14] J.B. van Helmont, Ortus Medicinae, Amsterdam, 1648, pp. 104-110.

[15] A.M. Amorim da Costa, Introdução à História e Filosofia das Ciências, Publicações Europa-América, 2. ${ }^{a}$ Edição, Lisboa, 2002, p. 31.

[16] I. Walton, The compleat angler or the contemplative man's recreation, London, 1653; Reedição de Sir Harris Nicolas, London, 1875, p. 31.

[17] R. Boyle, The sceptical chymist or chymico-physical doubts \& paradoxes, London, 1661.

[18] Nome por que ficou conhecida a rede de correspondência estabelecida no período de 1630-1660, liderada por Samuel Hartlib (1600-1662), o prussiano que depois de frequentar a Universidade de Cambridge, em 1628, se fixou permanentemente em Londres, onde se notabilizou como grande pensador e educador, e donde alimentou e manteve uma vasta correspondência sobre assuntos científicos com um vasto e notável grupo de filósofos naturais que viviam em Inglaterra, na Europa Ocidental e na Europa Central.

[19] A. Clericuzio, Elements, Principles and Corpuscles: A Study of Atomism and Chemistry in the Seventeenth Century, Springer-Science, Business Media, B.V., 2000.

[20] A.M. Alfonso-Goldfarb, M. Ferraz, As complexas transformações da ciência da matéria: entre o compósito do saber antigo e a especialização moderna, PUC-SP, Projecto Temático 99/12791-3.

[21] A.M. Alfonso-Goldfarb, M.H.M. Ferraz, P.M. Rattansi, Seventeenth-century 'treasure' found in Royal Society Archives: the Ludus helmontii and the stone disease, Notes Rec. Royal Soc. London 68 (2014) 227-244. Idem, Seventeenth-century experimenta, magisterial formulae and the 'animal alkahest': new documents found in Royal Society archives in Notes Rec. Royal Soc. J. History of Science 69 (2015) 395418.

[22] A. van Tubergen, S. van Linden, A brief history of spa therapy, Ann. Rheum. Dis. 61 (2002) 273-275.

[23] C.J.S. Thompson, The mystery and romance of alchemy and pharmacy, London, The Scientific press, Ltd., 1897. 